\title{
Age-related changes in BAFF and APRIL profiles and upregulation of BAFF and APRIL expression in patients with primary antibody deficiency
}

\author{
RONG JIN, HIDEO KANEKO, HIROKO SUZUKI, TAKAHIRO ARAI, \\ TAKAHIDE TERAMOTO, TOSHIYUKI FUKAO and NAOMI KONDO
}

Department of Pediatrics, Graduate School of Medicine, Gifu University, Gifu, Japan

Received September 24, 2007; Accepted November 19, 2007

\begin{abstract}
In some patients with common variable immunodeficiency (CVID) and immunoglobulin (Ig) A deficiency (IgAD), tumor necrosis factor (TNF) family receptor transmembrane activator and calcium-modulator and cyclophilin ligand interactor (TACI) gene mutations have been reported. B cells from individuals with TACI mutations do not produce IgG and IgA in response to the TACI ligand a proliferation-inducing ligand (APRIL) which probably suggests impaired isotype switching. To clarify the pathogenesis of CVID and IgAD of Japanese patients, we investigated the mutations of TNF family members TACI, APRIL, B-cell activating factor (BAFF), B-cell maturation antigen (BCMA) and BAFF receptor (BAFF-R) genes and the expression levels of BAFF and APRIL in patients with CVID, IgAD and X-linked agammaglobulinaemia (XLA). We also investigated the relationship between age and the blood plasma levels of BAFF and APRIL. The causative gene mutations of TNF family members in our patients were not detected. In healthy subjects, the BAFF and APRIL plasma
\end{abstract}

Correspondence to: Dr Hideo Kaneko, Department of Pediatrics, Graduate School of Medicine, Gifu University, 1-1 Yanagido, Gifu, Gifu 501-1194, Japan

E-mail: hideo@gifu-u.ac.jp

Abbreviations: CVID, common variable immunodeficiency; Ig, immunoglobulin; IgAD, IgA deficiency; TNF, tumor necrosis factor; TACI, transmembrane activator and calcium-modulator and cyclophilin ligand interactor; APRIL, a proliferation-inducing ligand; BAFF, B-cell activating factor; BCMA, B-cell maturation antigen; BAFF-R, BAFF receptor; XLA, X-linked agammaglobulinaemia; BTK, Bruton tyrosine kinase; SLE, systemic lupus erythematosus; PBMCs, peripheral blood mononuclear cells; ELISA, enzyme-linked immunosorbent assay

Key words: common variable immunodeficiency, IgA deficiency, B-cell activating factor, a proliferation-inducing ligand, transmembrane activator and calcium-modulator and cyclophilin ligand interactor, B-cell activating factor receptor, B-cell maturation antigen, polymorphism, expression levels correlated inversely with age. The BAFF and APRIL plasma levels of patients with CVID, IgAD and XLA were significantly higher than those of healthy children. Elevated BAFF and APRIL expression levels might partially reflect the common immunological feature of primary antibody deficiency.

\section{Introduction}

Common variable immunodeficiency (CVID) is a primary immunodeficiency disease characterized by absence of terminal B lymphocyte differentiation into plasma cells, resulting in hypogammaglobulinaemia, antibody deficiency, and recurrent bacterial infections (1-3). IgAD is the most common form of primary immunodeficiency. Ig AD is characterized by absence or a very low level $(<5 \mathrm{mg} / \mathrm{dl})$ of serum $\operatorname{IgA}$. Individuals with $\operatorname{IgAD}$ can be asymptomatic or predisposed to recurrent infections, particularly recurrent sinopulmonary and gastrointestinal infections (4-6).

The molecular bases of IgAD and most cases of CVID remain unknown, whereas X-linked agammaglobulinaemia (XLA) is caused by a defective BTK protein, which is indispensable for the development of mature B cells $(7,8)$. Some individuals initially present with $\operatorname{IgAD}$ and then develop CVID later. IgAD and CVID are often observed in members of the same family. These observations suggest that some cases of IgAD and CVID have a common etiology (9). In fact, some patients with CVID and some patients with IgAD show a TACI mutation, as well as a mutation in one of the BAFF and APRIL receptors, associated with CVID and IgAD (10). These results suggest that BAFF and APRIL play crucial roles in B-cell-related immunodeficiency diseases such as CVID and IgAD.

BAFF and APRIL are two closely related cytokines; they share two receptors, TACI and BCMA, which are found mainly on B cells and plasma cells. The third receptor specific for BAFF, BAFF-R, is also found mainly on B cells and plasma cells, but also on some subsets of $\mathrm{T}$ cells $(11,12)$. Thus far, no specific receptor for APRIL has been found, but it has been shown to bind to proteoglycans (13). BAFF and APRIL are produced constitutively by monocytes, macrophages, neutrophils, dendritic cells and osteoclasts. The binding of BAFF and APRIL to their receptors induces class switch recombination to IgG and IgA in human B cells $(14,15)$. 
Table I. Immunological characteristics of patients with CVID and IgAD.

\begin{tabular}{|c|c|c|c|c|c|c|c|c|}
\hline & \multirow[t]{2}{*}{ Sex } & \multirow[t]{2}{*}{ Age (years) } & \multicolumn{3}{|c|}{ Serum Ig (mg/dl) } & \multicolumn{3}{|c|}{ Lymph cell (\%) } \\
\hline & & & $\operatorname{IgG}$ & $\operatorname{IgA}$ & $\operatorname{IgM}$ & CD3 & CD19 & CD14 \\
\hline \multicolumn{9}{|c|}{ CVID } \\
\hline 1 & $\mathrm{~F}$ & 8 & 679 & 8 & 15 & 67.0 & 9.0 & 3.2 \\
\hline 2 & $\mathrm{~F}$ & 9 & 761 & 7 & 11 & 69.0 & 22.0 & 7.1 \\
\hline 3 & $\mathrm{~F}$ & 20 & 378 & 7 & 5 & 64.0 & 22.0 & 6.6 \\
\hline \multicolumn{9}{|c|}{ Selective IgAD } \\
\hline 1 & M & 10 & 1363 & $<5$ & 146 & 74.6 & 15.4 & 8.0 \\
\hline 2 & $\mathrm{~F}$ & 11 & 1640 & $<5$ & 117 & 71.3 & 19.3 & 3.3 \\
\hline 3 & $\mathrm{~F}$ & 17 & 1261 & $<5$ & 137 & 85.9 & 10.3 & 6.1 \\
\hline \multicolumn{9}{|c|}{ Partial IgAD } \\
\hline 4 & $\mathrm{~F}$ & 4 & 869 & 27 & 106 & 81.1 & 11.3 & 7.3 \\
\hline 5 & M & 4 & 887 & 45 & 101 & 71.2 & 17.9 & 9.0 \\
\hline 6 & $\mathrm{M}$ & 4 & 1223 & 17 & 120 & 61.2 & 20.0 & 5.2 \\
\hline 7 & $\mathrm{~F}$ & 3 & 1644 & 15 & 150 & 48.1 & 24.8 & 5.6 \\
\hline 8 & M & 4 & 1624 & 8 & 100 & 64.8 & 10.8 & 6.2 \\
\hline 9 & $\mathrm{M}$ & 14 & 717 & 5 & 184 & 63.0 & 22.9 & 6.2 \\
\hline 10 & $\mathrm{~F}$ & 7 & 913 & 12 & 105 & 69.0 & 21.6 & 5.7 \\
\hline 11 & $\mathrm{M}$ & 13 & 705 & 9 & 39 & 80.0 & 12.2 & 8.5 \\
\hline \multicolumn{9}{|c|}{ Controls } \\
\hline & $\mathrm{M} / \mathrm{F}$ & Adults & 639-1344 & $70-312$ & $40-240$ & $51-83$ & $5-21$ & \\
\hline
\end{tabular}

APRIL is highly expressed in tumors of various origins and poorly expressed in normal cells (16). The serum levels of BAFF and APRIL are elevated in patients with systemic lupus erythematosus (SLE) (17).

In this study, we report the increased BAFF and APRIL expression levels of patients with primary antibody deficiency. We found that the BAFF and APRIL expression levels are inversely correlated with age.

\section{Materials and methods}

Subjects. Forty-three healthy individuals (0-50 years of age) were enrolled as normal controls. The other subjects were three patients with primary CVID from different families, diagnosed on the basis of low immunoglobulin serum levels and the presence of circulating B cells, three patients with selective $\operatorname{Ig} A D$ with serum $\operatorname{Ig}$ A levels below the detection limit $(<5 \mathrm{mg} / \mathrm{dl})$, eight patients with partial IgAD with serum IgA levels $>5 \mathrm{mg} / \mathrm{dl}$ but with 2 SD below normal levels, and four XLA patients with a BTK mutation. All of the patients were Japanese. The immunological characteristics of the patients are shown in Table I.

Mutation analysis. Genomic DNA was extracted from whole blood and purified with a Sepa Gene kit (Sanko Junyaku, Tokyo, Japan). We determined all the exons of the BAFF and APRIL genes and the genes of their receptors, namely, TACI, BAFF-R and BCMA, in the patients with CVID and IgAD.
Primers were designed for regions flanking each exon of the genes of TNF family members, including the splice donor and acceptor recognition sites; the primer sequences are shown in Table II. The PCR conditions were as follows: denaturation at $94^{\circ} \mathrm{C}$ for $5 \mathrm{~min}$, followed by 40 cycles at $94^{\circ} \mathrm{C}$ for $1 \mathrm{~min}$, annealing at $54-60^{\circ} \mathrm{C}$ for $1 \mathrm{~min}$, and $72^{\circ} \mathrm{C}$ for $1 \mathrm{~min}$, and a final extension at $72^{\circ} \mathrm{C}$ for $7 \mathrm{~min}$. The BAFF-R gene was difficult to amplify because the percentages of $\mathrm{G}$ and $\mathrm{C}$ in the BAFF-R sequence were too high. We used the Takara LA Taq (Takara Bio Inc., Japan) with GC buffer enzyme for good performance of DNA amplification. The amplified fragments were subjected to direct sequencing.

Blood plasma BAFF and APRIL levels. The collected blood plasma was assayed for BAFF and APRIL by an enzymelinked immunosorbent assay (ELISA). Peripheral blood was obtained by venipuncture from patients with CVID, IgAD and XLA, and from 43 healthy subjects. The plasma samples were stored at $-20^{\circ} \mathrm{C}$ until use. Soluble BAFF was quantitated in blood plasma diluted 1:4 (plasma of XLA patients were diluted 1:9) using the ELISA kit from R\&D Systems, Inc. (Minneapolis, MN, USA). Enzyme activities were determined at an optical density of $450 \mathrm{~nm}$. APRIL was determined in the same plasma samples. The plasma was diluted 1:1 (plasma of CVID and XLA patients were diluted 1:4) using the ELISA kit from Bender MedSystems GmbH (Vienna, Austria). Enzyme activities were determined at an optical density of 450-650 nm. Both standard and samples were analysed in duplicate. 
Table II. Primer sequences used in this study.

\begin{tabular}{|c|c|c|}
\hline Exon & Forward primers & Reverse primers \\
\hline \multicolumn{3}{|c|}{ Primers for amplification and sequencing of TACI genomic DNA } \\
\hline 1 & 5'-GCCCGGCAGGCCTTCCACT-3' & 5'-GCAAGCCCCACATCCCAGAGG-3' \\
\hline 2 & 5'-TTCCCATCAGGGACAAGAGG-3' & 5'-CCTTTCCTCAGCCACCTGAC-3' \\
\hline 3 & 5'-CTTTGTGGTCAAACCCAGAG-3' & 5'-CTGGGCTTCATGCATTGTGG-3' \\
\hline 4 & 5'-CCAGCCTCTCCAGGAGCCAGAC-3' & 5'-CCGGGTGCCACTCTCCCAGTTA-3' \\
\hline 5 & 5'-CTGGGTCGGGGGAGAGTG-3' & 5'-СТСТTTCССТCTCTGCCTCT-3' \\
\hline
\end{tabular}

Primers for amplification and sequencing of APRIL genomic DNA

$\begin{array}{ll}1 & \text { 5'-ACCCCACTCTTGAAACCACA-3' } \\ 2 & \text { 5'-CCTTGACCCTCTTTCCATGA-3' } \\ 3 & \text { 5'-AGTCAGGGTGAGGGTGGAG-3' } \\ 4 & \text { 5'-TCCTGACCGACACACTCTCA-3' } \\ 5 & \text { 5'-GGCCATCCTGTTTTCTTCAA-3' } \\ 6 & \text { 5'-CTGTGCTTCACTGCGAATCT-3' }\end{array}$

\author{
5'-TGCTAACCATCCTCTCCCAG-3' \\ 5'-CACGCTGCTTGATCACCTC-3' \\ 5'-AGCCCGAGTTCCTGGTTATT-3' \\ 5'-CTCAGTAGGGGGCCAAAGAG-3' \\ 5'-TAGCTCCCTGCACTGCTACC-3' \\ 5'-ATGTACCCACCCTGGTCTTC-3'
}

Primers for amplification and sequencing of BAFF genomic DNA

$\begin{array}{ll}1 & \text { 5'-TGCCAGCAAACCTACTGTACAGT-3' } \\ 2 & \text { 5'-ACCACGCGGAGAAGCTGCCA-3' } \\ 3 & \text { 5'-TCAATGGGCAAATATAAAGTAACT-3' } \\ 4,5 & \text { 5'-GTGCAGTAATGTGACTTGTATTC-3' } \\ 6 & \text { 5'-TAGGCTAAGATAATTGCAATGGTT-3' }\end{array}$

5'-GGCACGCTTATTTCTGCTGTTC-3'
5'-CAGCGCTGGGGCTTTGCTCTA-3'
5'-AGCTTGCTGAGAATGATGGTTTC-3'
5'-ACAGACTAGCTTATTATTCAAGAT-3'
5'-TGGTATTTTCAGTTAGATTCTTTC-3'

Primers for amplification and sequencing of BAFF-R genomic DNA

$\begin{array}{ll}1 & \text { 5'-TCAGCCTCAGTCCCCGCAGCTTGT-3' } \\ 2 & \text { 5'-TGAAAGGACCCTGTGGGCAG-3' } \\ 3 & \text { 5'-TGGCCAGGCCTCTGGACTCA-3' }\end{array}$
5'-TGCCCACAGGGTCCTTTCAGCCCT-3'
5'-TCCGTTTCCCCTTAAAGCCC-3'
5'-TGAGGTCTGAAGCCAAAGGCAA-3'

Primers for amplification and sequencing of BCMA genomic DNA

\begin{tabular}{lll}
1 & 5'-GAAGCAGGCGAAGTTCATTGTT-3' & 5'-ATCAAGTTCAGTTCCAAATAATTAC-3' \\
2 & 5'-GAGGCAGGAGAATTGTTTGAACT-3' & 5'-GCTCACCTCTACCAAGTTCATTT-3' \\
3 & 5'-CTTGAGCCCAGGAGTTTGAAT-3' & 5'-CCATTAAGCTCCCAACAGTAAC-3' \\
\hline
\end{tabular}

Analyses of BAFF and APRIL gene expression. We carried out real-time PCR analysis to determine the levels of BAFF and APRIL mRNA in peripheral blood mononuclear cells (PBMCs). Total RNA was purified using an Isogen kit (Nippon Gene, Tokyo, Japan), subjected to DNase I treatment (RNA-free), and stored at $-80^{\circ} \mathrm{C}$. The primer set for human TNSF13B (GmbH Heidelberg) was used for BAFF. The primers for APRIL were as follows: forward 5-AGAATG GGGAAGGGTATCCC-3 and reverse 5-AGGTGCAGG ACAGAGTGCTG-3. Real-time PCR conditions were as follows: denaturation at $95^{\circ} \mathrm{C}$ for $10 \mathrm{~min}$, followed by 40 cycles at $95^{\circ} \mathrm{C}$ for $10 \mathrm{sec}, 64^{\circ} \mathrm{C}$ for $10 \mathrm{sec}$, and $72^{\circ} \mathrm{C}$ for $10 \mathrm{sec}$. The reaction was carried out using the LightCycler FastStart DNA Master SYBR-Green I kit (Roche GmbH, Mannheim, Germany) according to the manufacturer's instructions. The BAFF or APRIL copy number was standardized relative to GAPDH, and expressed relative to the amount of GAPDH mRNA as an $n=$ fold difference (18). No amplification of nonspecific products was observed.

Statistical analysis. Differences between the BAFF and APRIL protein and mRNA levels of the patients with CVID,
$\operatorname{IgAD}$, and XLA, and the controls were analyzed using the Student's t-test. The correlations between age and plasma levels of BAFF and APRIL were determined using Pearson's correlation coefficient test. $\mathrm{P}<0.05$ was considered statistically significant.

\section{Results}

We found polymorphism variants in the APRIL and TACI genes. The results are shown in Table III. Nucleotide sequencing revealed two variants at codon 67 in exon 1 and at codon 96 in exon 2 of the APRIL gene. Both variants were caused by a single nucleotide substitution. At amino acid residue 67 , the first nucleotide $\mathrm{G}$ was replaced by $\mathrm{A}$, which resulted in an amino acid change from Gly to Arg (G67R). At codon 96, the second nucleotide A was replaced by $\mathrm{G}$, which resulted in an amino acid change from Asn to Ser (N96S). These variants had the same frequencies in the control subjects. There were no other polymorphisms in the coding region of the human APRIL gene. Moreover, nucleotide sequencing revealed one variant at codon 251 in exon 5 of the TACI gene, which results in the amino acid substitution 
Table III. Summary of variants found in patients during the screening of TNF family members.

\begin{tabular}{|c|c|c|c|c|c|c|}
\hline & \multicolumn{2}{|c|}{ APRIL } & BAFF & TACI & BAFF-R & BCMA \\
\hline \multicolumn{7}{|l|}{ CVID } \\
\hline 1 & G67R (homo) & N96S (homo) & WT & P251L (hetero) & WT & WT \\
\hline 2 & WT & N96S (homo) & WT & P251L (hetero) & WT & WT \\
\hline 3 & G67R (hetero) & N96S (hetero) & WT & P251L (homo) & WT & WT \\
\hline \multicolumn{7}{|c|}{ Selective IgAD } \\
\hline 1 & G67R (hetero) & N96S (homo) & WT & P251L (hetero) & WT & WT \\
\hline 2 & WT & N96S (hetero) & WT & WT & WT & WT \\
\hline 3 & WT & N96S (homo) & WT & P251L (homo) & WT & WT \\
\hline \multicolumn{7}{|c|}{ Partial IgAD } \\
\hline 4 & G67R (homo) & N96S (homo) & WT & P251L (homo) & WT & WT \\
\hline 5 & G67R (hetero) & N96S (hetero) & WT & P251L (hetero) & WT & WT \\
\hline 6 & G67R (hetero) & N96S (hetero) & WT & P251L (hetero) & P21R (hetero) & WT \\
\hline 7 & G67R (hetero) & N96S (hetero) & WT & P251L (hetero) & WT & WT \\
\hline 8 & G67R (hetero) & N96S (homo) & WT & WT & P21R (hetero) & WT \\
\hline 9 & G67R (hetero) & N96S (hetero) & WT & WT & P21R (hetero) & WT \\
\hline 10 & WT & N96S (homo) & WT & P251L (homo) & WT & WT \\
\hline 11 & G67R (homo) & N96S (homo) & WT & WT & WT & WT \\
\hline \multirow[t]{3}{*}{ Control } & WT $\quad(n=24)$ & WT $\quad(n=5)$ & & WT $\quad(n=9)$ & WT $\quad(n=20)$ & \\
\hline & $\begin{array}{l}\text { G67R (hetero) } \\
\qquad(\mathrm{n}=20)\end{array}$ & $\begin{array}{l}\text { N96S (hetero) } \\
\qquad(\mathrm{n}=21)\end{array}$ & & $\begin{array}{l}\text { P251L (hetero) } \\
\qquad(\mathrm{n}=5)\end{array}$ & & \\
\hline & $\begin{array}{c}\text { G67R (homo) } \\
(\mathrm{n}=6)\end{array}$ & $\begin{array}{r}\text { N96S (homo) } \\
(\mathrm{n}=24)\end{array}$ & & $\begin{array}{l}\text { P251L (homo) } \\
\qquad(\mathrm{n}=3)\end{array}$ & & \\
\hline
\end{tabular}

homo, homozygous; hetero, heterozygous; WT, wild-type.

a

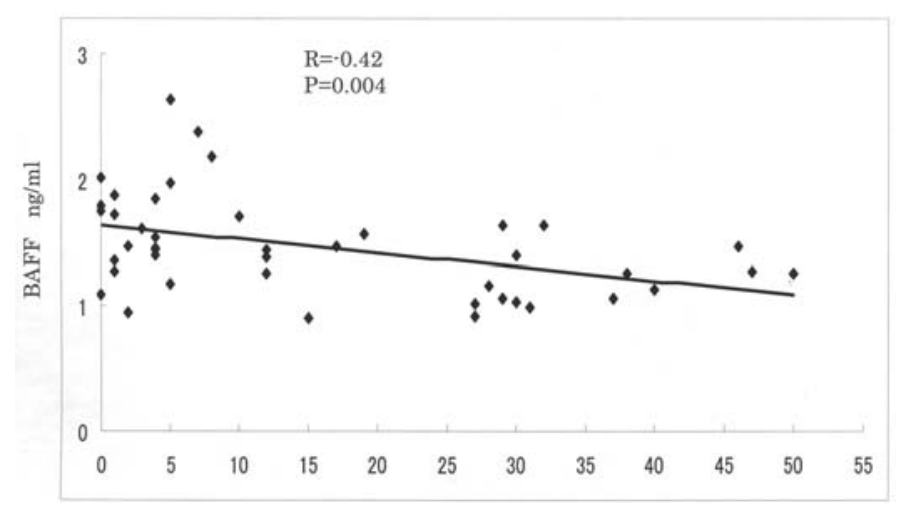

b

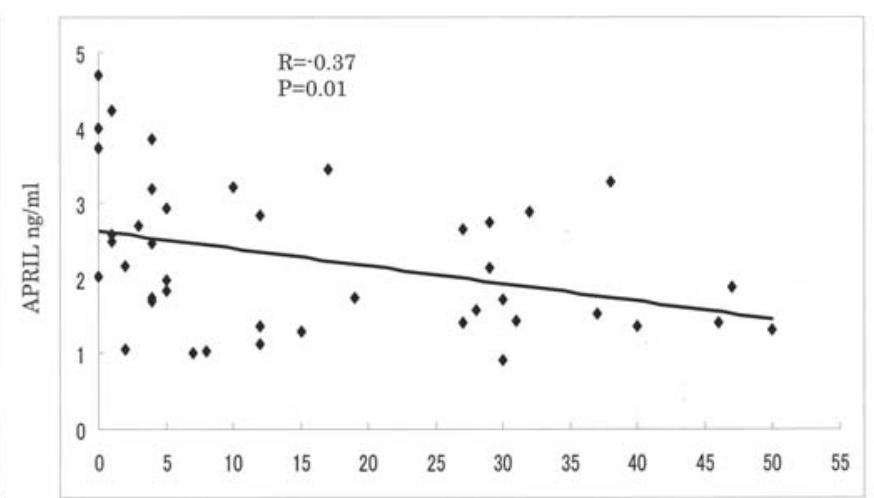

Figure 1. Inverse correlation of BAFF and APRIL plasma levels with age. BAFF and APRIL levels were determined in the same plasma samples ( $\mathrm{n}=43$ ). (a) Inverse correlation of BAFF plasma levels with age $(\mathrm{R}=-0.42, \mathrm{P}=0.004)$; (b) Inverse correlation of $\mathrm{APRIL}$ plasma levels with age $(\mathrm{R}=-0.37$, $\mathrm{P}=0.01)$.

P251L. This variant had the same frequency in the control subjects. Thus, the above nucleotide substitutions probably represent polymorphisms. In addition, we found a variant of the BAFF-R gene in three patients with partial IgAD. The variant was a heterozygous G-to-C substitution at position 62 in exon $1(62 \mathrm{C}>\mathrm{G} / \mathrm{wt})$, resulting in the replacement of the wild-type proline with an arginine $(\mathrm{P} 21 \mathrm{R} / \mathrm{wt})$, as previously reported (19). The sequence analysis showed that causative gene mutations of TNF family members, namely, TACI, BAFF-R, BCMA, and their ligands, namely, BAFF and APRIL were not detected in the patients with CVID and IgAD.

To compare the BAFF and APRIL levels of patients with primary antibody deficiency with those of healthy subjects, we measured the blood plasma levels of BAFF and APRIL in 


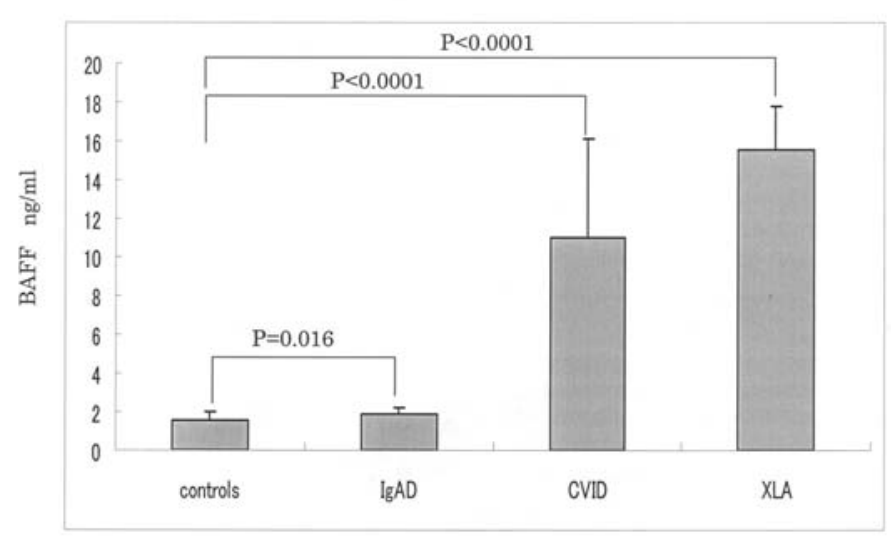

b

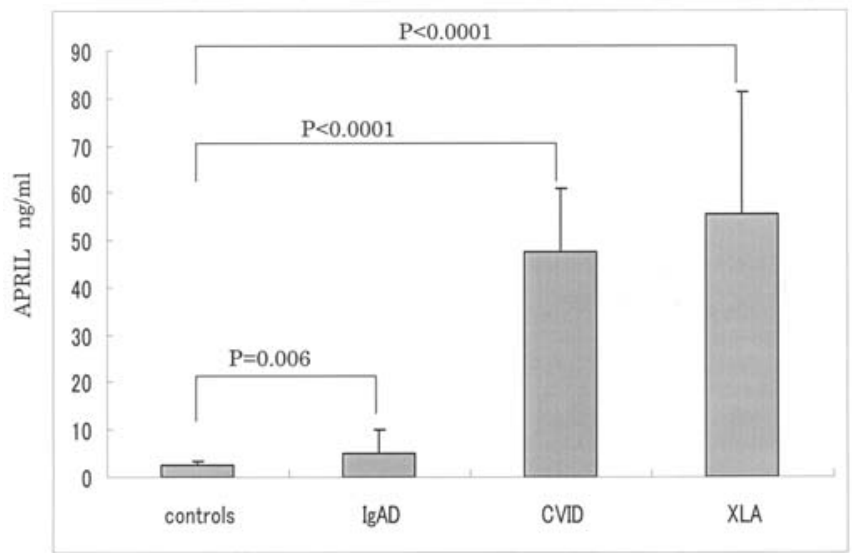

Figure 2. BAFF and APRIL protein expression levels of patients with IgAD, CVID and XLA. BAFF and APRIL levels were determined in the same plasma samples: plasma samples from 3 patients with CVID (mean age 12.3 years), 11 patients with IgAD (mean age 8.6 years), 4 patients with XLA (mean age 29 years) and 28 healthy children (control) (mean age 5.6 years). (a) BAFF protein expression levels of patients with CVID, IgAD and XLA. (b) APRIL protein expression levels of patients with CVID, IgAD and XLA.

a

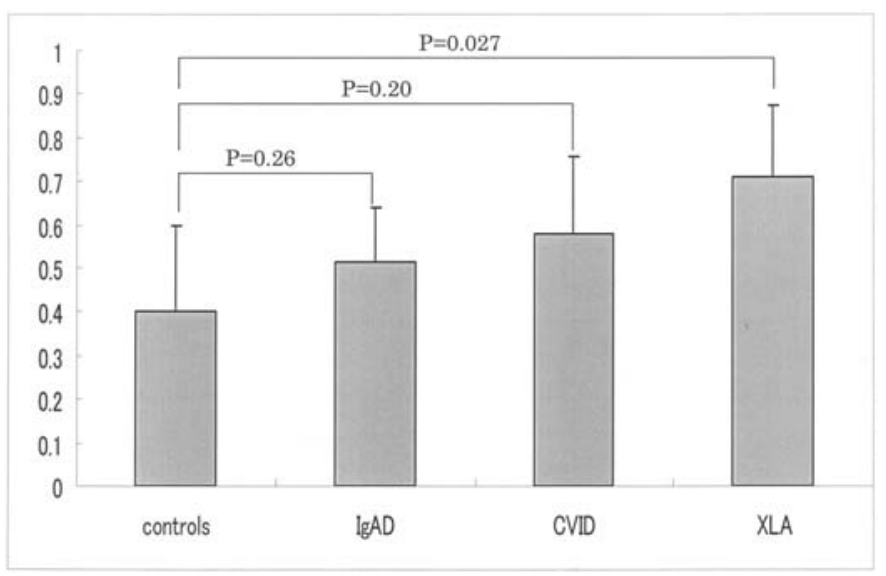

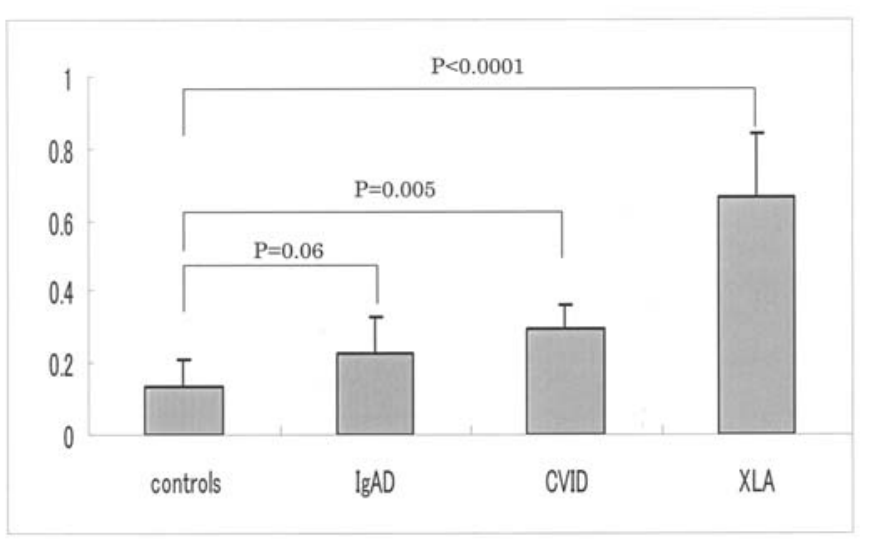

Figure 3. BAFF and APRIL gene expression levels in PBMCs of patients with CVID, IgAD and XLA. BAFF and APRIL gene expression levels of in 3 patients with CVID (mean age 12.3 years), 11 patients with IgAD (mean age 8.6 years), 4 patients with XLA (mean age 29 years) and 28 healthy children (control) (mean age 5.6 years). (a) BAFF mRNA. (b) APRIL mRNA.

43 healthy subjects of different ages. We found that the plasma levels of BAFF and APRIL were inversely correlated with age (BAFF: $\mathrm{R}=-0.42, \mathrm{P}=0.004$; APRIL: $\mathrm{R}=-0.37$, $\mathrm{P}=0.01$ ) (Fig. 1a and $\mathrm{b}$ ). The inverse correlation of BAFF and APRIL gene expression levels with age was not detected by semi-quantitative PCR analysis (data not shown).

Next, the BAFF and APRIL protein levels of 11 patients with IgAD, 3 patients with CVID, and 4 patients with XLA were measured. The patients with CVID, IgAD and XLA showed significantly higher plasma levels of BAFF and APRIL than 28 normal children (Fig. 2a and b). The median plasma levels of BAFF were $1.92 \mathrm{ng} / \mathrm{ml}$ for IgAD, $11.04 \mathrm{ng} /$ $\mathrm{ml}$ for CVID, $15.59 \mathrm{ng} / \mathrm{ml}$ for XLA and $1.59 \mathrm{ng} / \mathrm{ml}$ for the controls. The median plasma levels for APRIL were $5.2 \mathrm{ng} /$ $\mathrm{ml}$ for $\operatorname{IgAD}, 47.39 \mathrm{ng} / \mathrm{ml}$ for CVID, $55.59 \mathrm{ng} / \mathrm{ml}$ for XLA and $2.46 \mathrm{ng} / \mathrm{ml}$ for the control.
The BAFF gene expression levels of the patients with XLA and the APRIL gene expression levels of the patients with CVID and XLA were significantly higher than those of the healthy subjects (Fig. 3a and b). The median levels of BAFF mRNA were 0.52 for IgAD, 0.58 for CVID, 0.71 for XLA, and 0.40 for the controls. The median levels of the APRIL mRNA were 0.23 for IgAD, 0.30 for CVID, 0.66 for XLA and 0.14 for the controls.

\section{Discussion}

Two studies have shown that coding variants in the TACI gene are associated with primary immunodeficiencies in humans $(3,10)$. We found a P251L substitution in the TACI gene in patients with CVID and IgAD, and in the healthy subjects, which was consistent with previous findings (10). Moreover, 
the G67R and N96S variants in the APRIL gene were detected at the same ratio as that in the healthy subjects, as previously reported (20). In the BAFF-R gene, three patients with IgAD showed the P21R variant, whereas no healthy subjects presented this variant. However, these variants have been reported to have no effect on the BAFF-R function (19). Therefore, we concluded that no causative mutation of the genes of TNF family members was detected in our patients.

We showed that the BAFF and APRIL levels were upregulated in the plasma of patients with CVID, IgAD and XLA. These findings indicate that BAFF and APRIL are involved in the common pathogenesis of primary antibody deficiencies. If fewer B cells are present than can be sustained by BAFF, the circulating pool of BAFF becomes augmented, and in the case of a mouse with total B-cell deficiency, BAFF was found to reach its highest levels (21-23). Patients with XLA have the lowest numbers of B cells associated with primary antibody deficiencies, that is, CD19-positive B cells were $<0.1 \%(8)$. We showed that XLA is associated with the highest BAFF protein and gene expression levels. The low B-cell numbers might induce high BAFF gene expression levels to increase the number of B cells.

Recently, Knight et al have shown that CVID patients show a marked increase in the serum levels of BAFF, APRIL and TACI (18). Consistent with the results of their study, our findings revealed that primary immunodeficiency patients, including those with CVID, IgAD and XLA, showed increased plasma levels of BAFF and APRIL. It was suggested that primary antibody deficiency might have common immunological features such as monocyte activation (24-27). It has been reported that inflammation and cytokines such as IFN $\gamma$ or G-CSF in particular enhance BAFF production $(28,29)$.

In addition we found that the BAFF and APRIL plasma levels correlated inversely with age. It was also reported that the number of B cells is inversely correlated with age (30). In humans as well as in mice, the BAFF level might determine the size of the peripheral B-cell pool.

Although BAFF and APRIL are produced by many cells of the hematopoietic system, it is unclear how the expression and production of these cytokines are regulated. To understand the pathogenesis of primary antibody deficiency, it is necessary to elucidate the mechanism of the upregulation of BAFF and APRIL expression.

\section{Acknowledgements}

This study was partly supported by a grant from the Ministry of Health, Labor and Welfare of Japan.

\section{References}

1. Salzer U and Grimbacher B: Common variable immunodeficiency: The power of co-stimulation. Semin Immunol 18: 337-346, 2006.

2. Hammarstrom L, Vorechovsky I and Webster D: Selective IgA deficiency (SIgAD) and common variable immunodeficiency (CVID). Clin Exp Immunol 120: 225-231, 2000.

3. Salzer U, Chapel HM, Webster AD, Pan-Hammarström Q, Schmitt-Graeff A, et al: Mutations in TNFRSF13B encoding TACI are associated with common variable immunodeficiency in humans. Nat Genet 37: 820-828, 2005.

4. Asano T, Kaneko H, Terada T, et al: Molecular analysis of B-cell differentiation in selective or partial IgA deficiency. Clin Exp Immunol 136: 284-290, 2004.

5. Cunningham-Rundles C: Physiology of $\operatorname{IgA}$ and IgA deficiency. J Clin Immunol 21: 303-309, 2001.
6. Burrows PD and Cooper MD: IgA deficiency. Adv Immunol 65: 245-276, 1997.

7. Weston SA, Prasad ML, Mullighan CG, Chapel H and Benson EM: Assessment of male CVID patients for mutations in the Btk gene: how many have been misdiagnosed? Clin Exp Immunol 124: 465-469, 2001.

8. Kaneko H, Kawamoto N, Asano T, et al: Leaky phenotype of $\mathrm{X}$-linked agammaglobulinaemia in a Japanese family. Clin Exp Immunol 140: 520-523, 2005.

9. Castigli E and Geha RS: Molecular basis of common variable immunodeficiency. J Clin Immunol 117: 740-746, 2006.

10. Castigli E, Wilson SA, Garibyan L, Rachid R, Bonilla F, Schneider L, Geha RS, et al: TACI is mutant in common variable immunodeficiency and IgA deficiency. Nat Genet 37: 829-834, 2005

11. Bossen C and Schneider P: BAFF, APRIL and their receptors: Structure, function and signaling. Semin Immunol 18: 263-275, 2006.

12. Vallerskog T, Heimbürger M, Gunnarsson I, Zhou W, Wahren-Herlenius M, et al: Differential effects on BAFF and APRIL levels in rituximab-treated patients with systemic lupus erythematosus and rheumatoid arthritis. Arthritis Res Ther 8: R167, 2006.

13. Sakurai D, Hase H, Kanno Y, Kojima H, Okumura K, et al: TACI regulates IgA production by APRIL in collaboration with HSPG. Blood 109: 2961-2967, 2007.

14. Mackay F and Ambrose C: The TNF family members BAFF and APRIL: the growing complexity. Cytokine Growth Factor Rev 14: 311-324, 2003.

15. Matsushita $\mathrm{T}$ and Sato $\mathrm{S}$ : The role of BAFF in autoimmune diseases. Jpn J Clin Immunol 28: 333-342, 2005.

16. Tangye SG, Bryant VL, Cuss AK and Good KL: BAFF, APRIL and human B cell disorders. Semin Immunol 18: 305-317, 2006

17. Koyama T, Tsukamoto H, Miyagi Y, Himeji D, Otsuka J, et al: Raised serum APRIL levels in patients with systemic lupus erythematosus. Ann Rheum Dis 64: 1065-1067, 2005.

18. Knight AK, Radigan L, Marron T, Langs A, Zhang L, et al: High serum levels of BAFF, APRIL, and TACI in common variable immunodeficiency. Clin Immunol 124: 182-189, 2007.

19. Losi CG, Silini A, Fiorini C, Soresina A, Meini A, et al: Mutational analysis of human BAFF receptor TNFRSF13C (BAFF-R) in patients with common variable immunodeficiency. J Clin Immunol 25: 496-502, 2005.

20. Koyama T, Tsukamoto H, Masumoto K, Himeji D, Havashi K, et al: A novel polymorphism of the human APRIL gene is associated with systemic lupus erythematosus. Rheumatology 42: 980-985, 2003.

21. Schneider P: The role of APRIL and BAFF in lymphocyte activation. Curr Opin Immunol 17: 282-289, 2005.

22. Lesley R, Xu Y, Kalled SL, Hess DM, Schwab SR, et al: Reduced competitiveness of autoantigen-engaged B cells due to increased dependence on BAFF. Immunity 20: 441-453, 2004

23. Seyler TM, Park YW, Takemura S, Bram RJ, Kurtin PJ, et al: BLyS and APRIL in rheumatoid arthritis. J Clin Invest 115: 3083-3092, 2005.

24. Roschke V, Sosnovtseva S, Ward CD, Hong JS, Smith R, et al: BLyS and APRIL form biologically active heterotrimers that are expressed in patients with systemic immune-based rheumatic diseases. J Immunol 169: 4314-4321, 2002.

25. Mackay F, Sierro F, Gery ST and Gordon TP: The BAFF/ APRIL system: an important player in systemic rheumatic diseases. Curr Dir Autoimmun 8: 243-265, 2005.

26. Matsushita T, Hasegawa M, Yanaba K, Kodera M, Takehara K, et al: Elevated serum BAFF levels in patients with systemic sclerosis: enhanced BAFF signaling in systemic sclerosis B lymphocytes. Arthritis Rheum 54: 192-201, 2006.

27. Kawasaki A, Tsuchiya N, Fukazawa T, Hashimoto H and Tokunaga K: Analysis on the association of human BLYS (BAFF, TNFSF13B) polymorphisms with systemic lupus erythematosus and rheumatoid arthritis. Genes Immun 3: 424-429, 2002.

28. Nardelli B, Belvedere O, Roschke V, et al: Synthesis and release of B-lymphocyte stimulator from myeloid cells. Blood 97: 198-204, 2001.

29. Scapini P, Nardelli B, Nadali G, et al: G-CSF-stimulated neutrophils are a prominent source of functional BLyS. J Exp Med 197: 297-302, 2003.

30. Colonna-Romano G, Aquino A, Bulati M, Di Lorenzo G, Listi F, et al: Memory B cell subpopulations in the aged. Rejuvenation Res 9: 149-152, 2006. 